\title{
European Union Symbols under Threat: Identity Considerations
}

Laura Cram and Stratos Patrikios

Accepted Author Manuscript: In Kaina et al. (eds), European Identity Revisited:

New Approaches and Recent Empirical Evidence, Routledge (2016).

\begin{abstract}
This chapter discusses how experimental research using implicit visual cues can offer unique insights into the nature and consequences of territorial attachments in multilevel polities such as the European Union; how exposure to threat might impact on attitudes to the European Union; and how recent empirical efforts to illustrate the interaction of these two effects - exposure to visual stimuli and threat - point to a new research direction for students of European identity. The conclusion proposes empirical applications that extend recent research.
\end{abstract}




\section{INTRODUCTION}

Continued UK membership of the European Union (EU) increasingly appears to be under threat. A traditionally Eurosceptic nation, where even the presence of the EU flag in government buildings is a matter of controversy, Britain has exhibited consistently low levels of attachment to the EU in crossnational opinion surveys. Prime Minister Cameron has promised that in the event of a Conservative victory in 2015, he will hold a referendum on continued EU membership of his country. At the same time, the UK Independence Party (UKIP), an avowedly Eurosceptic party, gained an unprecedented 24 seats - one third of the UK's seats - at the European Parliament elections of 2014.

Yet, the most recent polls at the time of writing show support for EU membership in the UK to be peaking at its highest level in more than two decades (for example, IPSOS MORI Political Monitor, October 2014). This poses a crucial dilemma to any vote-seeking political actor with Eurosceptic aspirations: how much does one move in the direction of proposing an anti-EU vision to a relatively Eurosceptic public, before one triggers a Europhilic backlash among the same public? Understanding how individual attachment to the EU is shaped and how context interacts with and impacts on that attachment are matters of considerable contemporary interest.

This chapter discusses the following:

(i) How experimental research using implicit contextual stimuli (group symbols) that can activate group attachments offers insights into territorial attachment in multi-level polities such as the EU; 
(ii) How threat contexts might be expected to impact on attitudes to the European Union;

(iii) Recent attempts to measure the effect of exposure to threat and EU symbols on related attachments and preferences;

(iv) Proposed empirical applications that can extend the insights of current research.

Drawing on recent experimental studies, we argue that when presented in a context that implies even a subtle threat to the benefits of EU membership, EU symbols stop signifying the "them" to the national "us". Instead, they become symbols of a familiar status quo, which citizens are less willing to relinquish. The arguments and findings reviewed in this chapter are consistent with the recent upsurge in UK public support for continued EU membership, at a point at which the threat of exit has become an existential reality. The conclusion proposes ways in which the present research agenda can be enriched.

The chapter is structured as follows. The next section reviews recent experimental research on the psychology of group attachments, which employs implicit visual cues to examine the nature and impact of such attachments. This is followed by discussions of the instrumental connotations of group-related visual cues, and of the role of threat in fostering a fondness for the status quo as a coping mechanism to combat psychological stress. It is argued that this mechanism may lead to stronger "wefeelings" where previously these were absent or weak. Next, we review recent findings from experimental studies that manipulate individual exposure to EU symbols and threat in the field of EU identity studies. The conclusion proposes further 
experimental research that brings the field closer to actually measuring revealed rather than expressed (survey-based) outcomes.

\section{SYMBOLS AND GROUP ATTACHMENTS}

Identity processes - their formation, presence and consequences - are complex processes that are not easily expressed verbally. They entail a variety of socialpsychological components, which include (Abdelal et al. 2009):

- The objective categories of group membership that individuals use to define their self-image

- The cognitive and affective commitment of individuals to these categories

- Relative comparisons: positive attributes (stereotypes) attached to typical bearers of these categories; negative attributes attached to non-bearers

- Norms, symbols and social purposes attached to these categories

Despite the complex nature of the identity phenomenon, most existing methodological approaches to the study of group identity and attachment, in the EU context and elsewhere, rely exclusively on self-reported, verbal measures. In effect, researchers ask respondents directly to report - and, therefore, to rationalise about - their identities, motivations and preferences. Some type of correlational analysis is then employed to detect systematic patterns in the data.

In our research so far, we have used a more implicit strategy to measure EU attachment and its consequences. The implicit nature of this research draws on 
seminal conceptualisations of identity as banal and routine (Billig 1995). These have been applied recently to the study of EU identity, with an emphasis on how citizens are subjected to daily, subtle reminders of their involvement in the larger European Union system (Cram 2001, 2006, 2012; Manners 2011). These reminders do not have a "hot" or heroic form - an anthem, a map or a flag per se - but appear in unremarkable contexts (passports, currency, driving licences, and license plates). Still, these contexts remind citizens of their involvement in the EU system whether they favour or oppose that system.

The implicit character of these reminders dovetails with a key finding of recent empirical studies; namely, that a range of social-psychological phenomena including behaviours, attitudes and attachments - rest on automatic or "gut" reactions that may bypass cognitive awareness (for example, see an overview of research in social cognition in Hassin et al. 2005). In influential contributions, Hassin et al. (2007, 2009) primed identity processes among respondents by exposing them visually to national flags. Exposure to these cues interacted with existing attachment to affect relevant responses (see also Butz et al. 2007).

In particular, Hassin et al. (2009) found that subliminal exposure to the Israeli national flag had a homogenising effect on the political attitudes of individuals at extreme ends of the Israeli nationalist spectrum. Implicit priming with national flags affected both the stated voting intentions as well as the actual voting practice of participants in general elections (Hassin et al. 2009). In the United States, implicit exposure to the confederate flag significantly decreased the willingness of participants to vote for Barack Obama (Ehrlinger et al. 2011). Of particular relevance is the 
finding that implicit exposure to national symbols can enhance a sense of national identification and promote group belonging at an unconscious level, with associated effects on attitudes and behaviours (Butz 2009: 779).

The potential of the EU flag to promote a convergence in attitudes in the various member states is at the heart of many EU initiatives to promote a "Peoples' Europe". However, it has also been demonstrated experimentally that the impact of national state symbols may have a polarising impact depending on existing attachments. Drawing on social identification theory, Gilboa and Bodner (2009: 19) found that in the Israeli context adolescents, immigrants and particularly the ultra-religious were less likely to identify strong national associations with their national anthem. These insights are supported by Butz's (2009) reminder of the multi-referential nature of national symbols and of the ability of such symbols to provoke polarisation as well as convergence. Sachs's (2009) study of national and Islamic identities in Indonesia also revealed the capacity of national symbols to provoke disunity and specifically to invoke discord amongst groups that felt disadvantaged within the national context.

\section{SYMBOLS AND INSTRUMENTAL BENEFITS}

The attachment of symbols to instrumental benefits is an essential part of the creation and maintenance of a sense of identification with a political regime. Benefits of regime membership, whether material or otherwise, can become associated with symbols denoting attachment such as flags and national anthems. These symbols, over time, begin to function as a cognitive short cut. As the symbols begin to resonate with 
the public, even at an unconscious level, they become capable of mobilising "national", or in this case, "EU" sentiment.

Deutsch (1966:172-173) argued early on that, in order to understand the process of identity building, we needed to study the secondary symbols that carry implicit messages about nationhood. The extent to which these secondary symbols had become attached to daily events and patterns of communication is of particular interest. Deutsch, thus, argued that a detailed mapping exercise of national symbols and their functions was required. Billig (1995: 175), referring to the nation state, also argued that there was a need for a taxonomy of national "flaggings".

Symbols appear to play an important role in forging a European Union identity (Shore 1993; Laffan 1996; Bruter 2003, 2009; McLaren 2006; Manners 2011). Certainly, the EU institutions have employed considerable resources in an attempt to generate meaningful EU symbols that resonate with national publics. However, there is still much to learn about how the EU symbol impacts, in practice, on attitudes and behaviours in the various member-states and even beyond. A question of particular interest is whether and to what extent the context in which the EU symbol is displayed can shape mass attitudes.

Key to understanding the process of European Union identity formation is an appreciation of the nature and complexities of the relationship between European Union identity and the range of national state identities and sub-state national identities with which it interacts. National identity is not contiguous with member state borders. The EU as an institution provides a context within which calculations as 
to the contingent benefits of affiliation with any given level of administration are made. In the multi-level and multi-national system of the EU, the processes through which existing and emerging identities interact, and how the EU institutional structure and external contexts impact upon this process, require detailed analysis.

As Butz argues (2009: 797), 'particular types of associations may be activated and become influential in different contexts and situations'. Sachs (2009) cautions political entrepreneurs that attempts to promote national unity through explicit attempts at identity manipulation may diverge significantly from their initial intentions. This caution is particularly relevant for the complex EU context with respect to explicit top-down exercises of identity building.

\section{SYMBOLS UNDER THREAT}

As the recent UK case suggests, the instrumental benefits associated with identity processes (for example, a country's membership of the EU) can come under threat. The presence of threat has cognitive, behavioural and motivational effects for individuals and groups (Jost et al. 2003; Thorisdottir/Jost 2011; Pantoja/Segura 2012). These effects are predominantly in a direction that favours the status quo, in an attempt to manage uncertainty. It has been argued, for example, that 'there may be a general tendency for individuals, groups, and organisations to behave rigidly in threatening situations' (Staw et al. 2007: 502). Lavine et al. (2005: 221) also suggest that threat 'provides the primary motivation for the internalisation of society's prescriptions (conventionalism), submission to perceived legitimate authority, and aggression against out-groups'. They argue that the presence of threat alters not only 
what authoritarians think, but how they think, and find that threat increases the extent to which authoritarians act in line with their existing predispositions and encourages high authoritarians towards biased, rather than open-minded, information processing (Lavine et al. 2005: 240). Perrin (2005) confirms the link between conservative authoritarian attitudes and the experience of threat. Pantoja and Segura (2012) provide evidence that a threatening context, in their case a threatening environment for Latinos in California, has consequences for the process of learning and political information gathering. Specifically, immigrants in California are motivated by a hostile context to become more knowledgeable for the purpose of political selfdefence.

Threat is also known to hold a central role in influencing inter-group relations. It plays a key part in shaping and consolidating a sense of "us" and "them". Early studies of intergroup conflict in boys' camps, for instance, identified the significant role played by external threat in creating internal group cohesion (Sherif/Sherif 1953; Sherif et al. 1961). External threats have more generally been shown to draw group members closer together and to strengthen in-group cohesiveness (Staw et al. 2007: $507)$.

Deutsch et al. (1957) have theorised about the process in which emerging patterns of attachment to a political unit are consolidated once the benefits associated with that unit come under risk (see also Cram 2012). This expectation also dovetails with Wlezien's "thermostatic" view of the responsiveness of public opinion to elite initiatives (Wlezien 1995). Franklin and Wlezien (1997) have applied this model to study the link between the volume of EU integration policies and public preferences 
on integration. They find that when Brussels policies moved too much in the direction of integration the public adjusted its preferences to the opposite direction asking for less integration. The operation of this negative feedback mechanism depends on whether the EU issue is salient or not.

These points are applicable in the context of EU attachment. The UK example is a helpful illustration. When the element of threat is not prominent, in what could be described as normal political circumstances, the EU system exists as the "other" to the UK "us". The reasons for the negative, relative to other large European nations, stance of the British public and their political elites on the EU can be explained on the basis of instrumental, economic considerations and national identity concerns. However, when the EU system and Britain's position in it come under threat, as in the recent case, the EU might be regarded as the "us" to an undefined "them".

\section{AN EXPERIMENTAL ILLUSTRATION}

In our earlier research we examined the effect of implicit exposure to the EU symbol (Cram/Patrikios 2015; see the Appendix for a summary of the research design). This was achieved by exposing participants to photographic images that had been manipulated to include or exclude the EU symbol. The measurement of the relevant preferences and other personal characteristics was administered by a short questionnaire that followed exposure. The symbol was only part of a larger scene and not the main focus of the image. This work used British public opinion data collected in online survey experiments, and established that the underlying identity processes 
that linked exposure to the symbol and related opinions were of a functional, "banal" nature (Billig 1995).

Specifically, we found that implicitly exposing participants to the EU symbol in an instrumental setting (photo of passport control checkpoint at airport), and not in the abstract, had an impact on their opinions regarding the practical benefits of the EU. The way this implicit effect operated reinforced pre-existing feelings of attachment to the EU in a polarising way; specifically, those attached to the EU reacted to the EU symbol by providing more pro-EU responses than the control group; those not attached to the EU reacted to the EU symbol by providing more anti-EU responses than the control group.

Our more recent work (Patrikios/Cram, forthcoming; see the Appendix) used a small Scottish student sample to establish what would happen to the instrumental connection described if placed under threat. Threat was introduced as a subtle textual manipulation. In detail, participants were asked to complete a short survey questionnaire with a front page that combined image and text, plus instructions. There were four possible combinations. The page combined versions of a photographic image (airport passport checkpoint with or without the EU symbol) with an excerpt from a mock news story. The story was worded without any mention of the "EU" or "Europe" or national referents, but made reference to a "terror threat disrupting travel plans" or had a neutral content for the control group. We found that exposure to the EU symbol produce more positive responses towards the EU only when presented within a threatening context. 


\section{CONCLUSION AND A RESEARCH AGENDA}

The chapter reviewed recent empirical attempts to measure the impact of threat exposure on EU attachment in an implicit manner, one that gauges "gut" reactions and bypasses the biases of the standard measurement strategies relying on selfreports. The experimental strategy presented so far relies on the implicit exposure of individuals to implicit threat cues related to practical benefits of their country's membership to the EU. The benefits are focused on the ease of movement across the EU. Threat exposure is accompanied by subtle exposure to a key EU symbol. Both these elements, implicit threat and visual cue, create a situation where individual respondents are primed to consider the potential risks to the practical benefits of EU membership for their country. The consequences of this priming are positive for EU attachments and preferences.

Measuring these consequences would have been very difficult had we only relied on self-reported measures; for instance, if we simply asked respondents about their attachments, their EU-related opinions, and made the threat to the EU explicit as part of question wording (e.g. as an opening statement). That would inevitably trigger known desirability biases, where respondents would be aware of what answers are "expected" of them. UKIP supporters, for example, would be tempted to provide negative opinions on the EU irrespective of contextual manipulation. The use of implicit cues helps us bypass some of these biases.

However, our approach does not take us as far away from these biases as we might want to go. We still have to rely on expressed consequences of our experimental 
manipulation, as we use self-reports of EU-related preferences and attachments. A range of game-theoretic paradigms previously used in economics, psychology, and political science would permit the measurement of revealed preferences. These are ideal for avoiding the losses to validity that come with verbal measures. We review two applications in this final section.

Instead of asking respondents to answer a survey question as a measure of their EUrelated opinions, a "dictator" game would ask participants to divide a sum of money between themselves and some anonymous recipient, as they saw fit (for example, Forsythe et al. 1994; Hoffman et al. 1994; Fowler/Kam 2007). Contrary to the expectations of traditional rational choice theory, individuals usually share an amount of the initial sum with anonymous recipients. In this version, a subject acting as the dictator will have either no visual information about the recipient (control condition) or information as to recipient's group membership (a flag that reveals EU or other group membership). The game would shed light on the impact of EU-related cues on other-regarding behaviour, solidarity and generosity between EU member states. We expect that exposure to the EU cue (compared to exposure to the control cue or even some national cue) would lead to different allocation distributions.

In another application, research could use the "stag hunt" game in which participants must choose between cooperating with the other player to hunt a riskier, but more valuable payoff or to go it alone for a surer, less valuable result (for example, see Battalio et al. 2001). Again, implicit visual cues could be used to specify the other player's group (control, EU or national). The expectation is that EU primed subjects may show higher levels of cooperation than control subjects, but maybe lower than 
national primed subjects. Apart from incorporating the threat element in the form of financial loss, this game provides a more robust tool for examining the impact of identity on behaviour, as researchers can manipulate the payoff function (risk vs. reward) parametrically and determine critical ranges of values for cooperation as a function of implicit identity-related processes.

These applications would help students of EU identity to measure behavioural - and not self-reported behavioural - consequences of exposure to related visual cues under threat in a way that would entirely bypass desirability biases that affect the psychology of survey response. The applications can provide a potentially rich source of information, which addresses the impact of identity on politically relevant behaviour (generosity, cooperation, and trust). They allow for the assessment of identity as fundamentally affective or rational by whether or not it promotes rational or non-rational behaviour in games where such behaviour is well defined and measured. 


\section{BIBLIOGRAPHY}

Abdelal, Rawi, Herrera, Yshiko M., Johnston, Alistair I. and McDermott Rose (eds) (2009). Measuring Identity. Cambridge: Cambridge University Press.

Battalio, Raymond, Samuelson, Larry and Van Huyck, John (2001). 'Optimization Incentives and Coordination Failure in Laboratory Stag Hunt Games', Econometrica 69(3): 749-764.

Billig, Michael (1995). Banal Nationalism. London: Sage.

Bruter, Michael (2003). 'Winning Hearts and Minds for Europe: The Impact of News and Symbols on Civic and Cultural European Identity', Comparative Political Studies 36(10): 1148-1179.

Bruter, Michael (2009). 'Time Bomb? The Dynamic Effect of News and Symbols on Political Identity of European Citizens', Comparative Political Studies 42(12): 1498- 1536.

Butz, David A., Plant, E. Ashby and Doerr, Celeste E. (2007). 'Liberty and Justice for All? Implications of Exposure to the U.S. Flag for Intergroup Relations', Personality \& Social Psychology Bulletin 33(3): 396-408.

Butz, David A. (2009). 'National Symbols as Agents of Psychological and Social Change', Political Psychology 30(5): 779-804.

Cram, Laura (2012). 'Does the EU Need a Navel? Implicit and Explicit Identification with the European Union', Journal of Common Market Studies 50(1): 71-86.

Cram, Laura (2006). 'Inventing the People'. In Smismans, S (ed.). Civil Society and Legitimate European Governance. Cheltenham: Edward Elgar Publishing. 
Cram, Laura (2001). 'Imagining the Union: A Case of Banal Europeanism?'. In Wallace, H. (ed.). Interlocking Dimensions of European Integration. London: Palgrave.

Cram, Laura and Patrikios, Stratos (2015). 'Visual Primes and EU Identity: Designing Experimental Research’. In Lynggaard, K., Löfgren, K. and Manners, I. (eds.). Research Methods in European Union Studies. Basingstoke: Palgrave.

Deutsch, Karl W., Burrell, Sidney A., Kann, Robert A., Lee, Maurice Jr, Lichterman, Martin, Lindgren, Raymond E., Loewenheim, Francis L. and Van Wagenen, Richard W. (1957). Political Community and the North Atlantic Area. New York: Greenwood.

Deutsch, Karl W. (1966). Nationalism and Social Communication (2nd edn). New York: MIT Press.

Ehrlinger, Joyce, Plant, E. Ashby, Eibach, Richard P., Columb, Corey J., Goplen, Joanna L., Kunstman, Jonathan W., and Butz, David A. (2011). 'How Exposure to the Confederate Flag Affects Willingness to Vote for Barack Obama', Political Psychology 32(1): 131-146.

Forsythe, Robert, Horowitz, Joel L., Savin, N.E. and Sefton, Martin (1994). 'Fairness in Simple Bargaining Experiments', Games and Economic Behavior 6(3): 347 369.

Fowler, James H. and Kam, Cindy D. (2007). 'Beyond the Self: Social Identity, Altruism, and Political Participation', Journal of Politics 69(3): 811-825.

Franklin, Mark N. and Wlezien, Christopher (1997). 'The Responsive Public: Issue Salience, Policy Change, and Preferences for European Unification', Journal of Theoretical Politics 9(3): 347-363. 
Gilboa, Avi and Bodner, Ehud (2009). 'What Are Your Thoughts When the National Anthem is Playing? An Empirical Exploration', Psychology of Music 37(4), 459484.

Hassin, Ran R., Uleman, James S. and Bargh, John A. (eds) (2005). The New Unconscious. New York: Oxford University Press.

Hassin, Ran R., Ferguson, Melissa J., Kardosh, Rasha, Porter, Shanette C., Carter, Travis J. and Dudareva, Veronika (2009). 'Précis of Implicit Nationalism', Annals of the New York Academy of Sciences 1167: 135-145.

Hassin, Ran R., Ferguson, Melissa J., Shidlovski, Daniella and Gross, Tamar (2007). 'Subliminal Exposure to National Flags Affects Political Thought and Behavior', Proceedings of the National Academy of Sciences of the United States of America 104(50): 19757-19761.

Hoffman, Elizabeth, McCabe, Kevin and Smith, Vernon L. (1994). 'Preferences, Property Rights, and Anonymity in Bargaining Games', Games and Economic Behavior 7(3): 346-380.

Jost, John T., Glaser, Jack, Kruglanski, Arie W. and Sulloway, Frank J. (2003). 'Political Conservatism as Motivated Social Cognition', Psychological Bulletin 129(3): 339-375.

Laffan, Brigid (1996). 'The Politics of Identity and Political Order in Europe', Journal of Common Market Studies 34(1), 81-102.

Lavine, Howard, Lodge, Milton and Freitas, Kate (2005). 'Threat, Authoritarianism, and Selective Exposure', Political Psychology 26(2): 219-244.

McLaren, Lauren M. (2006). Identity, Interests and Attitudes to European Integration. London: Palgrave. 
Manners, Ian J. (2011). ‘Symbolism in European Integration', Comparative European Politics 9(3): 243-268.

Pantoja, A. D. and Segura, G. M. (2012). 'Far in California and Loathing: Contextual Threat and Political Sophistication Among Latino Voters', Political Behaviour 25(3): 265-286.

Patrikios, Stratos and Cram, Laura (forthcoming). 'Better the Devil you Know: Threat Effects and Attachment to the European Union', Comparative European Politics.

Perrin, Andrew J. (2005). 'National Threat and Political Culture: Authoritarianism, Anti-Authoritarianism, and the September 11 Attacks', Political Psychology 26(2): 167-194.

Sachs, Natan B. (2009). 'Experimenting with Identity: Islam, Nationalism and Ethnicity', Paper presented at the Annual Meeting of the American Political Science Association, Toronto.

Sherif, Muzafer and Sherif, Carolyn W. (1953). Groups in Harmony and Tension: An Introduction to Studies in lntergroup Relations. New York: Harper and Row.

Sherif, Muzafer, Harvey, O. J., White, Jack B., Hood, William R., and Sherif, Carolyn W. (1961). Intergroup Conflict and Cooperation: The Robbers Cave Experiment. Norman, OK: University Book Exchange.

Shore, Cris (2000). Building Europe: The Cultural Politics of European Integration. London: Routledge.

Staw, Barry M., Sandelands, Lance E. and Dutton, Jane E. (2007). 'Threat Rigidity Effects in Organizational Behaviour: A Multilevel Analysis', Administrative Science Quarterly 26(4): 501-524. 
Thorisdottir, Hulda and Jost, John T. (2011). 'Closed Mindedness Mediates the Effects of Threat on Political Conservatism', Political Psychology 32(5): 785811.

Wlezien, Christopher. (1995). 'The Public as Thermostat: Dynamics of Preferences for Spending', American Journal of Political Science 39(4): 981-1000. 


\section{APPENDIX}

\section{A1. Experiment details (Cram/Patrikios 2015)}

The research was conducted online with UK territorial samples. Respondents were exposed to an implicit visual cue related to the EU (the control group did not receive the EU cue) in the form of either a flag decorating a public building or the EU symbol at passport control. The image appeared as the introduction screen to the survey. The short survey asked questions about EU-related attitudes and preferences, which were replicated from Eurobarometer surveys. The responses of participants exposed to the EU related image were compared to the responses of control participants, which were not exposed to the EU symbol. For further details and visual aids, see Cram and Patrikios (2015).

\section{A2. Experiment details (Patrikios/Cram, forthcoming)}

The research team placed four versions of a printed questionnaire face-down in separate sections of the lecture theatre. Each of the four versions contained a different cover page, which combined the visual and textual manipulations $(2 \times 2)$. The short survey attached to the cover page was identical across the four versions. Each version of the questionnaire corresponded to a different section of the lecture theatre. The sections were separated from each other. Students were randomly assigned to one of the four sections upon arrival in class, and were asked only to first read the cover page very carefully, and then to complete the short survey. For further details and visual aids, see Patrikios and Cram (forthcoming). 